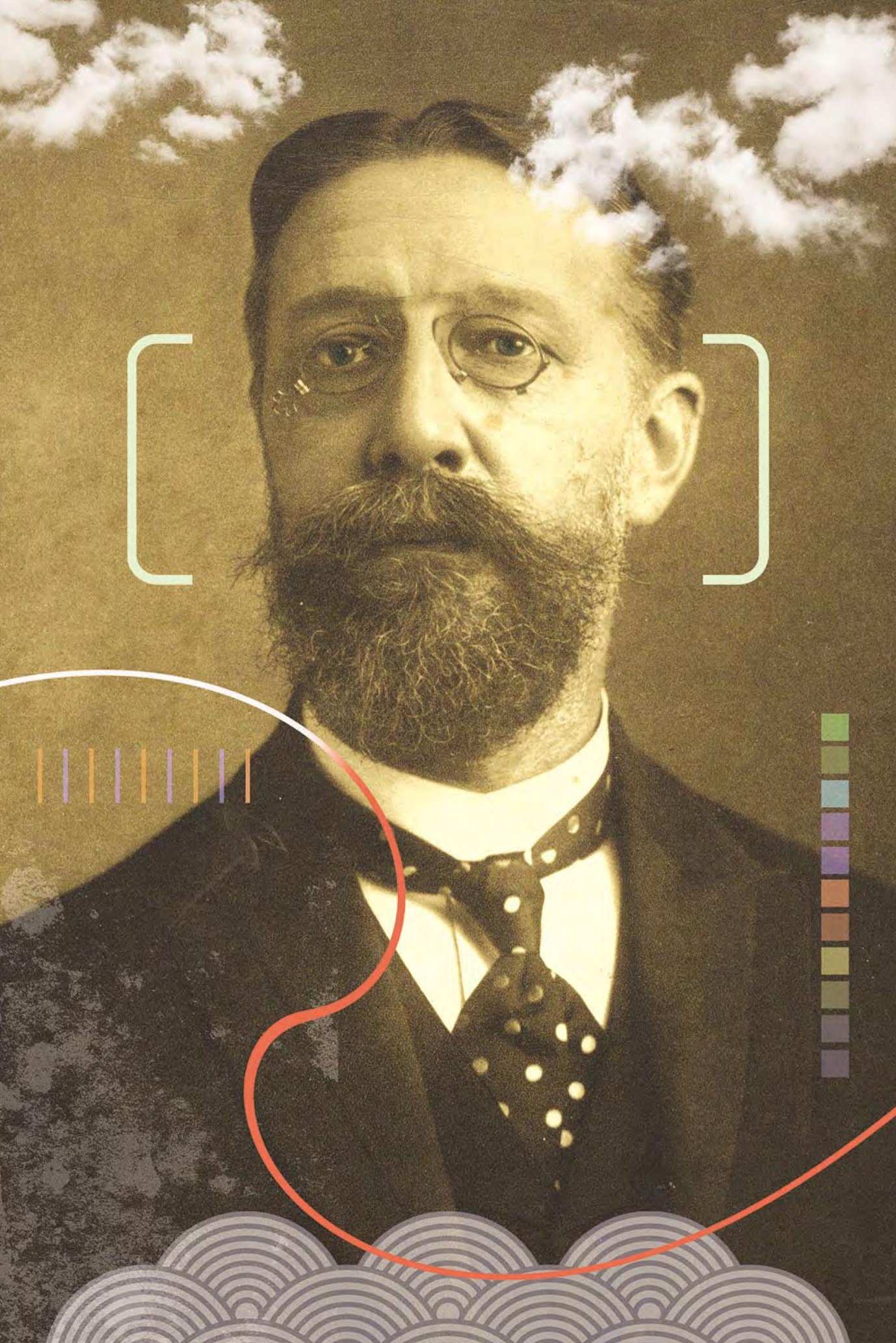




\title{
Max Weber e a nova economia institucional: normas e convenções sociois em Axelrod, Bicchieri, North, Ostrom
}

\author{
Max Weber and the New Institutional \\ Economics: social norms and conventions in \\ Axelrod, Bicchieri, North, Ostrom
}

${ }^{*}$ Bonnie Azevedo
${ }^{* *}$ Ronaldo Fiani

\section{Resumo}

Este artigo analisa normas e convenções sociais na Nova Economia Institucional (NEI), especialmente em Bicchieri, Axelrod, North e Ostrom à luz de conceitos weberianos como usos, costumes, convenções e normas jurídicas. Defende-se que o descumprimento de tais 'normas' e 'convenções'é mais grave do que é assumido pela NEl. Concluise que, embora tenham observado algumas consequências do descumprimento dessas regularidades sociais, os autores minimizaram a relevância das sanções dele decorrentes. Exatamente nesta lacuna, espera-se que a análise neoinstitucional mais se beneficie de um contraponto weberiano de resolução de conflitos e ensejo ao comportamento cooperativo.

Palavras-chave: Weber, Nova Economia Institucional, normas e convenções sociais, cooperação.

\begin{abstract}
This paper analyses social norms and conventions in New Institutional Economics (NIE), especially in Bicchieri, Axelrod, North and Ostrom, inspired by weberian's concepts of customs, conventions and rule of law. It's argued that the breach of such 'rules of law' and 'conventions' is more serious than it's assumed by NIE's authors. The conclusion reinforces that they observed some consequences of noncompliance, but they've minimized the relevancy of the resulting sanctions. It's a gap of neoinstitucional analysis that could benefits from a Weberian contrast consideration on conflict resolution and stimulates cooperative behavior.
\end{abstract}

Keywords: Weber, New Institutional Economics, social norms and conventions, cooperation.

\footnotetext{
* Doutora em Políticas Públicas, Estratégia e Desenvolvimento pelo PPED da Universidade Federal do Rio de Janeiro. Currículo Lattes: http://lattes.cnpq.br/1257690025069736.

E-mail: bonnieazevedo@gmail.com

** Professor Associado - Instituto de Economia/Universidade Federal do Rio de Janeiro. Currículo Lattes: http:// lattes.cnpq.br/7394437376053050.

E-mail: fiani@ie.ufrj.br
} 


\section{Introdução ${ }^{1}$}

Este artigo discute alguns conceitos weberianos - usos, costumes, convenções e normas jurídicas - para melhor compreender a ordem jurídica e os conceitos de normas e convenções sociais nas obras de alguns autores da chamada Nova Economia Institucional $\left(\mathrm{NEI}^{2}\right)$.

Em leituras exploratórias, identificou-se uma superficialidade na forma como tais conceitos são abordados pela NEI. A contraposição feita pela NEI entre semelhanças e antagonismos de normas e convenções sociais será contraposta aos conceitos weberianos supracitados. Weber é o autor escolhido para essa análise da NEl porque, economista, jurista e sociólogo, entre outras formações, conciliou a influência da escolha racional do agente com a importância dos constrangimentos da aprovação/ reprovação social.

Priorizam-se os conceitos e análises propostos por Bicchieri (2006) e Ostrom (1990), complementados pela discussão de North (1990, 1992, 1994) e Axelrod (2010, 1997), comparando-os, todos, aos conceitos weberianos mencionados. Bicchieri (2006) e Ostrom (1990) procuraram responder, etimológica e analiticamente, à discussão sobre normas e convenções sociais. North (1990, 1992, 1994) e Axelrod (1997, 2010) desenvolveram este tema, com foco na influência das instituições informais na promoção da cooperação ('regras do jogo', formais e informais) bem como das respectivas sanções em caso de descumprimento. Trata-se de um tema difundido na literatura das ciências sociais que buscou compreender a ordem social, suas estruturas e mecanismos de administração de conflitos (a desordem).

A seguir, narra-se duas situações do cotidiano: a primeira, em uma organização militar $\left(\mathrm{OM}^{3}\right)$, na qual hierarquia e disciplina são valores maiores, juridicamente assegurados pelos regimentos internos de tais organizações; a segunda, sobre o comportamento - socialmente aceito - de ceder o lugar aos idosos nos transportes coletivos. A partir delas, os conceitos são comparados substantivamente, em sua definição e discussão. Defende-se que o próprio entrave à cooperação é uma das sanções mais expressivas de se desconsiderar, deturpar ou confundir a natureza dos constrangimentos sociais envolvidos nas negociações individuais e coletivas, sendo, portanto, o descumprimento de 'normas' e'convenções' mais grave do que é assumido pela NEI.

\section{Narrativa $1^{4}$}

Nas organizações militares, hierarquia e disciplina são codificadas como normas jurídicas, condutas desejáveis e obrigatórias. Seus membros podem, caso ocorra ofensa a tais princípios, 'dar parte' de um 'desviante' - em termos durkheiminianos - ou 'prestar queixa' - o equivalente na linguagem da norma jurídica comum.

Algumas OMs funcionam em regime de internato. Seus membros moram e trabalham e/ou estudam nela. Já no soar dos alarmes das refeições, a hierarquia 
é anunciada e praticada na formação da fila do refeitório. Aqueles que ainda não são oficiais, são liberados para fazer suas refeições em ordem hierárquica, a partir do toque de 4 alarmes, um para cada nível hierárquico envolvido. Primeiro o $4^{\circ}$ ano, e depois, sucessivamente, o $3^{\circ}$, o $2^{\circ}$ e o $1^{\circ}$. Assim, existe uma organização para que as filas se formem entre aqueles de mesmo nível hierárquico. Isso não impede eventuais atrasos de algum indivíduo hierarquicamente superior, que o leve a comparecer no refeitório no momento em que a fila apenas está formada por seus subalternos. Nessa ocasião, três possibilidades foram relatadas por $Z^{5}$ (o hierarquicamente superior):

1. Esperar no final da fila;

2. Os seus subalternos Ihe oferecem o primeiro lugar da fila - o mais privilegiado, atitude esperada diante dos valores organizacionais;

3. Ausente a alternativa 2 e Z não disposto à opção $1, Z$ faz valer seu direito de ocupar o melhor lugar da fila.

No caso da opção 3, o indivíduo reforça sua hierarquia, estatuída pela organização, 'na marra'. Os que se recusam a seguir a previsão traduzida na alternativa 2, são considerados por $Z$, indivíduos desviantes à norma e, por essa razão, de caráter duvidoso. Assumir o desvio como falha de caráter é ainda mais comum quando o 'desviante' é conhecido por se desviar da regra quando essa lhe prejudica, mas invocála quando ele é o beneficiado. Este 'finge que não vê' o superior, assim se abstendo de obedecer, como se fosse relapso, distraído. Não seguir a alternativa 2, protocolo informal da OM, na concepção de Z, torna o descumpridor da norma não apenas um profissional como também um ser humano não-confiável, irresponsável, mau-caráter. Isto porque não se submeter à regra é não sucumbir à hierarquia que favorece outro, prejudicando-o. Z apresentou uma quarta possibilidade:

4. Adotara opção 1 atéo momento em queX, subalterno de Z, chega posteriormente e reforça seu direito sobre seus próprios subalternos (Ys), ignorando a presença de $Z$ na fila e, portanto, ignorando a regra em prejuízo de $Z$, apenas para cumprila em seu favor $(X)$. Nesse caso, narrado por $Z$ como o mais indigno porque 0 provoca, como um insulto pessoal, moral, leva-o a passar à frente de $\mathrm{X}$ e todos os Ys presentes, para cumprir a regra tal como deveria ser cumprida, originalmente. Assim, Z demonstra a todos como 'erraram', descumprindo a regra, sem prejudicar ninguém. Estaria apenas cumprindo uma regra, a qual, supostamente, todos concordaram em obedecer ao juntarem-se à OM.

Para Z, o indivíduo que ignora essa norma jurídica que vale para todos na OM, seria igualmente capaz de ferir as normas e convenções da sociedade como um todo. Ferir uma regra socialmente aceita (dentro da OM, ou na sociedade civil), atenta contra um valor que deveria ser preservado. Por essa razão, não seria apenas descumpridor da 
norma, mas por consequência e em última análise, um mau-caráter, por cumprir a regra apenas quando é favorecido por ela.

Para reforçar o argumento central de sua narrativa, Z citou casos em que adolescentes ou adultos cedem o lugar no ônibus para um idoso como uma situação equivalente. Mas aqui que essa história começa a se tornar mais complexa, pois envolve normas e convenções sociais simultaneamente. Vejamos por quê.

\section{Narrativa 2}

Essa narrativa diz respeito a ceder ou não o lugar ao idoso no ônibus. Quando há a presença de um idoso:

1. Os não idosos sentados no banco destinado aos idosos e não cedem o lugar aos que possuem tal direito, podem sofrer sanções legais e/ou morais;

2. Os não idosos sentados nos demais assentos, podem sentir-se moralmente obrigados a ceder seu lugar aos idosos, uma vez que os assentos destinados a estes estão ocupados por não-idosos, ou mesmo quando ocupados por idosos, porque a lei somente assegura $10 \%$ dos assentos para idosos.

Segundo a Lei Federal 10.741/2003, (...) artigo 39 (...). Além da gratuidade, também é assegurado no parágrafo Il que nos veículos de transporte coletivo (...) serão reservados $10 \%$ (dez por cento) dos assentos para os idosos, devidamente identificados com a placa de reservado preferencialmente para idosos. ${ }^{6}$

As situações 1 e 2 se desdobram de formas distintas. No primeiro momento, se um passageiro não idoso sentar no lugar reservado, há diversas possibilidades. Entre elas:

1. O passageiro cede o lugar;

2. O passageiro não cede o lugar e o idoso reclama seu direito;

3. O passageiro não cede o lugar e o motorista ou o trocador, responsáveis pela condução do veículo e, pela consequente execução de todas as normas de trânsito e segurança implicadas, reclama o direito do idoso;

4. O passageiro não cede o lugar e outros passageiros reclamam o direito do idoso (sem ceder seu assento não preferencial);

5. Outros passageiros reclamam o direito do idoso, e independente de o indivíduo que estava no assento preferencial ceder o lugar, cedem seu assento não preferencial ao idoso;

E na situação em que há mais idosos que assentos preferenciais (10\% dos assentos pela lei supracitada):

6.1. Ou os passageiros dos demais assentos cedem o lugar (por valores morais traduzidos na convenção social); 
6.2. Ou não cedem o lugar (não pactuando com tais valores morais, por desconhecê-lo ou por discordância consciente).

Nas situações dos itens 2, 3, 5, passageiros criam um constrangimento legal e moral ao não-idoso (que pode ou não senti-lo) ao ocuparem o assento preferencial e não cederem o lugar. Contudo, como o trajeto de ônibus é uma situação transitória, as sanções poderiam ser consideradas amenas, porque ao descer do ônibus, o indivíduo "zeraria" sua reputação diante dos demais membros da sociedade, pois é remota a possibilidade daquele grupo encontrar-se em sua formação novamente ou, encontrando-se, reconhecerem-se.

O item 4 é ambíguo. Aquele que reclama ao que está sentado no assento preferencial do idoso o dever legal/jurídico de ceder o lugar, pode ser vítima de resposta grosseira de que, caso incomodado, pode ele mesmo ceder seu lugar ao idoso. Se o passageiro do assento não-preferencial não cede seu lugar, está descumprindo um costume, em termos weberianos, que prevê a cessão do assento de não-idosos aos idosos, porém não está descumprindo nenhuma norma ${ }^{7}$, pois está nos $90 \%$ de assentos não preferenciais. Os passageiros, no caso do item 6, não descumprem norma jurídica ou costume.

Assim, sob as regras acordadas pelos membros da sociedade brasileira nas suas convenções, posteriormente, emerge uma lei: o Estatuto do Idoso. Weber discute essa transição como processo comum da ordem social.

(...) sempre é fluida a transição entre a simples aceitação apática da habituação inconsciente a determinada ação e a adoção consciente da máxima de uma ação correspondente à norma. Do mesmo modo que a simples regularidade efetiva de uma ação engendra convicções morais e jurídicas de conteúdo correspondente, a circunstância, por outro lado, de que meios coativos físicos e psíquicos imporem determinado comportamento cria a habituação efetiva e, por isso, a regularidade das ações. (Weber 1999: 220)

Contudo, rompimentos às normas e convenções são recorrentes. A fim de entender melhor ambas situações, discute-se alguns desses conceitos e como contribuem para o entendimento da questão.

\section{Implicações teóricas e práticas das narrativas}

Para Cristina Bicchieri (2006), Elionor Ostrom (1990) e Douglas North (1990) ‘normas e convenções sociais' são dois tipos básicos de instituições informais ${ }^{8}$ que descrevem e representam a ordem espontânea, tema de estudo amplamente trabalhado pela escola austríaca do pensamento econômico. Por instituições informais entende-se o conjunto de regras sociais que não é codificado e garantido por autoridade política formalmente constituída. O conjunto dessas instituições informais configuraria um ordenamento social estabelecido de forma não intencional, por meio da cristalização de regras de interação adotadas por indivíduos e gradualmente difundidas pelo grupo 
a que eles pertencem. Esse ordenamento constituiria uma ordem espontânea à medida que as regras adotadas pelos indivíduos não resultariam da intenção de ordenar a sociedade, mas apenas da necessidade de ordenar e solucionar um problema de interação individual.

Na tradição dos estudos da ordem espontânea ${ }^{9}$, as regras sociais não emanam da autoridade política externa, mas se estabelecem de maneira natural na sociedade (FIANI, 2011, p. 109-110), sendo denominadas por North 'restrições informais' (1990, p. 36). Uma das questões centrais aos estudos institucionais do último século foi se a ordem espontânea produziria instituições mais adequadas do que as estabelecidas por uma autoridade política e, se aquelas levariam, consequentemente, à cooperação e assim ao progresso social. Isso porque, se a cooperação que resulta da ordem espontânea produz o melhor resultado, seria desnecessária ou pouco relevante uma autoridade política reguladora, e com ela órgãos públicos de administração de conflito, planejamento e construção de estratégias para o desenvolvimento.

North ressalta que uma das mudanças mais marcantes que passamos na história da economia foi a transição de um mercado cujas transações eram respaldadas por relações pessoais, para um em que as relações impessoais passaram a caracterizar a maior parte das transações, levando a uma série de mudanças conexas, juntamente a esta transformação. Nas sociedades de relações pessoais, comuns nas sociedades mais tradicionais, como as narradas em diversos textos antropológicos ${ }^{10}$ normas sociais forneciam a base compartilhada de conhecimento a partir da qual ocorriam as ações de toda a coletividade. Na sociedade moderna, de conhecimentos e informações intensivos, de transformações constantes e velozes, a cooperação é anônima e os modelos mentais dos indivíduos muito diversos. Em um mundo de informações incompletas, os riscos de conflitos são maiores. Criam-se instituições - third-party enforcement - para assegurar as transações e diminuir seus custos (NORTH, 1994, p. 57 apud ABRAMOVAY, 2004, p. 52)

Third-party enforcement means the development of the state as a coercive force able to monitor property rights and enforce contracts effectively, but no one at this stage in our knowledge knows how to create such a entity... Put simply, if the state has coercive force, then those who run the state will use that force in their own interest at the expense of the rest of the society. (North, 1990, p.59)

Os custos de transação são parte das mudanças conexas à transição da ordem social e dos mercados baseados em relações pessoais para relações impessoais. Nas relações pessoais ou de longa duração, confiança, reputação, tradição e outros atributos intangíveis estão envolvidos. Logo, os custos de transação são baixos e o third-party enforcement sequer é necessário.

Com o aumento das trocas, em seus volumes, bens, tipos de acordos, entre outros, tornou-se necessário construir mecanismos que permitissem a ampliação das escalas de troca e começaram as primeiras relações de troca impessoais, ainda sem o thirdparty enforcement. A evolução das regras informais para as formais, até a compilação 
delas em uma Constituição, é um processo que envolve diferentes elementos da vida social, nos quais constrangimentos formais e institucionais se misturam (North, 1990). As constituições aparecem como o elemento chave para assegurar o enforcement bem sucedido, isto é, sem abusos e assegurando que os interesses de grupos distintos não sejam suprimidos pelo poder do governante do Estado. Elas seriam o resultado das condições políticas e da opinião pública e não o contrário (RIKER, 1976, p. 13 apud NORTH, 1990, p. 60).

No início do período moderno, o Estado aumentou seu papel como regulador dessas trocas e passou a exercer o third-party enforcement, por excelência. $O$ cenário das sociedades modernas, repleto de transações entre agentes econômicos que possuem informação incompleta, necessita de instituições que garantam os contratos - mecanismos de enforcement e third-party enforcement. Elas proveem um mecanismo de comunicação comum entre as partes, informando as sanções a que estão submetidas e incentivando os responsáveis pelo enforcement a agir, se necessário (NORTH, 1990, p. 57).

Contudo, lançar mão desse mecanismo de enforcement para o cumprimento dos acordos deveria ser exceção (NORTH, 1990, p. 35), ou mesmo desnecessário, porque é a forma mais custosa de garantir os resultados das transações, e baixos custos de transação são imprescindíveis para a eficiência. Além disso, existem formas diversas de assegurar a conformidade das partes aos termos da troca. Entre elas, as instituições informais estão entre os menos custosos e mais poderosos. Crenças comuns e ideologias, valores de honestidade e integridade, todos atuam como eficazes mecanismos de enforcement ${ }^{11}$.

Em regra, há uma síntese no processo de evolução das instituições discutidas, que podem ser assim traduzidas

\begin{abstract}
A hierarchy of rules - constitutional, statute law, common law (and even bylaws) together will define the formal structure of rights in a specific exchange. Moreover, a contract will be written with enforcement characteristics of exchange in mind. Because of the costliness of measurement, most contracts will be incomplete; hence informal constraints will play a major role in the actual agreement. These will include reputation, broadly accepted standards of conduct (effective to the extent that the conduct of the other parties is readily observable), and conventions that emerge from repetitive interactions. The relationship between rights and constraints in an exchange can be illustrated at three levels: first at the level of a single straightforward exchange, second in the more complex relationship involved in the production process, and finally for the economy as a whole. (NORTH, 1990, p.61)
\end{abstract}

Quando discutimos enforcement há uma barganha entre sociedade e instituições/ organizações, entre empreendedores e principais (sociedade civil em geral e grupos de interesse), entre empreendedores de interesses distintos (governante versus legislativo, governante versus governante, governante versus organizações nacionais e internacionais que regulam as trocas). 
North questionou como seria possível manter a cooperação em relações impessoais (era moderna), isto é, como criar incentivos, mecanismos de enforcement, e outros fomentos ao desenvolvimento. Historicamente, o que muda a matriz de recompensas é a criação de novas instituições. Assim, as instituições definem os incentivos que, por sua vez, definem a matriz de recompensas, estimulando os indivíduos a cooperar ou não. Se quanto maior a especialização, a divisão do trabalho e o tamanho dos mercados, mais complexa a rede de instituições políticas e econômicas necessárias para assegurar a coordenação entre agentes e garantir acordos, mais necessárias são as instituições.

A NEl afirma que há muito mais que o auto interesse nas ações dos indivíduos no mercado. Portanto, não haveria apenas ações baseadas em uma racionalidade perfeita na qual a simetria de informações tornaria desnecessária a existência das instituições. Para North, não apenas não há auto regulação - isto é, a ordem espontânea dos mercados não leva ao equilíbrio geral dos mercados -, mas sem as instituições, os custos de transação são imensuráveis porque "(...) não envolvem apenas um problema simples de informação, mas diferenças nos sistemas de crenças que determinam a ação social" (ABRAMOVAY, 2004, p. 51).

Normas e convenções sociais eram os principais mecanismos reguladores das sociedades tradicionais, antes que tivessem instrumentos para formalizar a lei, o Estado e demais instituições/organizações reguladoras. Normas e convenções sociais eram informadas pelos valores morais inestimáveis ao grupo social. Quanto mais intenso o laço social promovido pelas relações pessoais, mais intensa a relevância das normas sociais e menores os custos de transação. Por essa razão, embora muitos defendam a evolução institucional das sociedades menos complexas para as sociedades modernas (ocidentais) como sinal de desenvolvimento, North acredita que instituições ineficientes sobreviveram em razão dos ganhos que rendiam aos governantes, ao produzir baixos custos de transação.

The breakdown of personal exchange is not just the breakdown of a dense communication network, but is the breakdown of communities of common ideologies and of a common set of rules in which all believe. The rise of impersonal rules and contracts means the rise of the State, and with it unequal distribution of coercive power. This provides the opportunity for individuals with superior coercive power to enforce the rules to their advantage, regardless of their effects on efficiency. That is, rules will be devised and enforced on behalf of the interests of the politically advantaged but they will not necessarily lower the costs of transacting in total. (NORTH, 1989, p. 1321)

Em grandes mercados de transações impessoais, novos mecanismos de enforcement passaram a ser necessários, sendo o mais importante deles o próprio Estado, força coercitiva no domínio econômico e político. Assim como North, Weber apontará que o Estado e seu aparato coativo estatal é fundamental em uma ordem social de relações impessoais, embora ressalte que 
(...) do ponto de vista sociológico, a crença no caráter imperativo, jurídico ou convencional de determinado comportamento é primariamente apenas um aditivo que aumenta o grau de probabilidade com o qual o agente pode contar em relação a determinadas consequências de suas ações. (WEBER, 1999, p. 220)

Bicchieri (2006) e Ostrom (1990) não explicitam o conteúdo substantivo e as diferenças entre "normas e convenções sociais". Há definições consagradas de normas e convenções entre os autores da NEl. Há mesmo autores que se referem apenas a normas como sinônimos de regras espontâneas; outros apenas às convenções, para designar o mesmo tipo de regra social. Quando conceituados separadamente, normas são regras sociais espontâneas cujo descumprimento acarreta sanções sociais para quem as desobedeceu, enquanto o descumprimento de convenções não incorreria em sanções (POSNER, 2000; BICCHIERI, 2006). Estes autores consideram que convenções sustentam-se apenas pelos ganhos mútuos que a coordenação das decisões daqueles que as seguem proporciona (VOSS, 2001, p. 109). Em suma, o custo para o indivíduo que desobedece a uma convenção social seria apenas o de não conseguir comunicarse e coordenar suas ações com os demais membros do grupo seguidores da norma (BICCHIERI, 2006; FIANI, 2011).

$E$, sendo assim, questiona-se aqui o que eles podem estar desconsiderando acerca das consequências das sanções sociais impostas aos que contrariam as normas sociais vigentes? Entendendo a cultura como a gramática simbólica com a qual enxergamos o mundo (GEERTZ, 1989, 2002), e a ordem social ${ }^{12}$ como fruto das regularidades da conduta humana e das orientações de fato verificadas na realidade social - que podem ser motivadas por costumes, convenções, interesses particulares ${ }^{13}$, entre outros (WEBER, 1999) - como construir ou, ao menos, criar condições propícias à cooperação a partir de uma melhor compreensão de como as "normas e convenções sociais" informam o comportamento?

Para Bicchieri (2006), convenções assumem significado semelhante ao conceito de costumes em Weber (1999), isto é: um comportamento tipicamente regular, mantido nos seus limites tradicionais por seu caráter habitual e imitação irrefletida, cuja continuação ninguém exige do indivíduo ${ }^{14}$. Seu conceito de convenções está vinculado às dinâmicas de coordenação e expectativas mútuas, embora estas não sejam suficientes ao cumprimento da convenção. Um indivíduo obedece à convenção à medida que entende que a coordenação que essa obediência proporciona, resulta em vantagem específica para ele. Weber concordaria, considerando seus argumentos sobre a submissão individual às regularidades coletivas.

Já Axelrod $(2010,1997)$ testou o desempenho de diferentes estratégias para o surgimento espontâneo de convenções sociais voltadas à cooperação. Conduziu simulações de jogos de computador, testando vários programas e o jogo cuja estratégia obtivesse as maiores recompensas seria o vencedor. Em todas as rodadas de testes, a estratégia convencionalmente chamada "olho por olho", na qual o primeiro jogador coopera e nas jogadas subsequentes imita-se a jogada imediatamente anterior do 
oponente, até que este coopere por si mesmo (demonstrando boa vontade), obteve maior sucesso. Axelrod concluiu que essa estratégia é a representação de uma norma social bem-sucedida, e assim "normas sociais" induzindo a cooperação evoluiriam espontaneamente, bastando que os indivíduos interagissem entre $\mathrm{si}^{15}$, confirmando algumas das conclusões da escola austríaca sobre a ordem espontânea.

Como as normas se sustentam por muito tempo e podem ser transformadas em um período relativamente curto em relação ao passado (séculos de manutenção versus duas décadas de transição, por exemplo), costumam ficar mais visíveis quando são desafiadas (AXELROD, 1997, p. 46). Embora muitos estudem as normas sob a perspectiva das expectativas e dos valores envolvidos, não respondem como elas estão inseridas no comportamento. Para Axelrod (1997, p. 47), "A norm exists in a given social setting to the extent that individuals usually act in a certain way and are often punished when seen not to be acting in this way".

Axelrod (1997, p. 47) visava descobrir quando a cooperação baseada nas normas emerge $e^{\prime \prime}(. .$.$) to learn what conditions favor the development of norms so that$ cooperation can be promoted where it might not otherwise exist or be secure", baseado no dilema do prisioneiro envolvendo vários jogadores. A mudança nas normas aponta que as pessoas usam o mecanismo de tentativa e erro em vez de cálculos elaborados baseados em crenças sobre o futuro. Assim, as melhores estratégias sobreviverão, enquanto as piores serão descartadas, adotando claramente uma estratégia evolucionária (AXELROD, 1997, p. 47). Seus resultados mostraram que era preciso outro mecanismo para que as normas emergissem e se tornassem estáveis, algo que explicasse a emergência de normas para a cooperação entre vários jogadores, a "metanorma", além de outros mecanismos de estabilização da ordem e da cooperação.

A economia separa as normas sociais das metanormas. As metanormas seriam aquelas que punem não apenas o transgressor, mas aqueles que tiveram uma oportunidade de punir o transgressor e não o fizeram (AXELROD, 1997, p. 41). Axelrod aponta, assim como Granovetter (1978), que indivíduos estão dispostos a agir se os demais agirem primeiro (AXELROD 1997, p. 42). Para provar a relevância das normas, Axelrod relata o duelo de Alexander Hamilton, em 1804, mesmo quando todas as razões indicavam que a melhor estratégia era não duelar. O duelo ocorreu porque Hamilton considerou as sanções sociais que Ihe seriam impostas, caso declinasse, mais importantes do que os resultados de perder (inclusive, a própria vida). Encontra-se outro exemplo no sistema "Viva e deixe viver", traduzido por uma ética entre soldados nas trincheiras durante a I Guerra Mundial em prol da paz. Um oficial britânico registrou

I was having tea with A Company when we heard a lot of shouting and went out to investigate. We found our men and the Germans standing on their respective parapets. Suddenly a salvo arrived but did no damage. Naturally both sides got down and our men started swearing at the Germans, when all at once a brave German got onto his parapet and shouted out: "We are very sorry about that; we hope no one 
was hurt. It is not our fault. It is that damned Prussian artillery (RUTTER, 1934, p. 29 apud AXELROD, 1997, p. 40)

Ainda restaria saber o que faria uma norma se estabelecer se ninguém tivesse incentivos a punir a deserção? Sociólogos como Durkheim entendem que o papel da norma é punir o transgressor e manter a ordem social ao mostrar a todos os demais qual é o comportamento socialmente aceito, obrigando a coletividade a imputar a sanção.

Quando a ousadia pode crescer desproporcionalmente pela ausência da aplicação dos mecanismos punitivos, a norma colapsa. Esse resultado levou Axelrod a investigar quais mecanismos poderiam estabelecer as normas. O mecanismo que mais se destaca é a metanorma (punir aquele que observou uma deserção e não puniu o desertor), mas não é o único.

Um traço marcante da metanorma é que ela torna a norma auto policiável, porque não compensa a ninguém ser ousado (AXELROD, 1997, p. 52-55). A metanorma vinga o que deserta e o que sabe da deserção e não o delata ou pune, porque nesse sistema, é entendido que agir assim também é uma forma de desertar do grupo, agindo contrário ao seu benefício. "The types of defection we are most angry about are likely to be the ones whose toleration also makes us angry" (AXELROD, 1997, p. 55).

Há outros mecanismos que ajudam a estabelecer uma norma que é estabelecida apenas parcialmente. Quando uma norma é internalizada, os custos psicológicos de desertar são muito altos, mesmo quando há benefícios na deserção (AXELROD 1997, p. 57). Portanto, em um grupo em que uma norma alcança a internalização, a norma é estável. Pais e algumas instituições como igrejas, escolas, governos promovem essa internalização por meio de diversos mecanismos de educação e aprendizagem, mas seu sucesso depende de fatores diversos como "(...) the degree to which the individual identifies with the group and the degree to which the norm and its sponsors are seen as legitimate" (AXELROD, 1997, p. 57).

Além disso, passado e futuro afetam diretamente o comportamento dos jogadores. Axelrod mostrou que a probabilidade da continuidade da interação, interfere diretamente sobre as ações cooperativas presentes, também consideradas a partir das jogadas anteriores e que orientam a decisão sobre a cooperação ou deserção ${ }^{16}$.

Cumprir o que é socialmente aceito é psicologicamente importante para reforçar os vínculos de pertencimento grupal. Para Axelrod (1997, p. 58-9), há uma propensão a adotar as normas pelo mecanismo da "prova social". A "social proof" da psicologia social seria o comportamento correto. Negá-lo, geraria altos custos. Observá-lo, por outro lado, informa-nos o limite socialmente tolerado de ousadia, isto é, o momento em que acionam-se mecanismos de punição. São as ações dos demais que informam o comportamento apropriado.

Quando o que está em jogo é como as normas interferem na intensidade do vínculo indivíduo versus grupo, Axelrod defende que “(...) cooperators have a stronger 
ethical and group regarding impulse than defectors, a fator that led them to cooperate in the first place" (1997, p. 60) e permanecerem no grupo. Trata-se do pertencimento voluntário de um indivíduo a um grupo que possui fins comuns. Por isso, normas sociais tendem a ser muito fortes em sociedades coletivistas e mais forte nelas do que nas individualistas.

Diversas leis vigentes, antes foram normas. "Norms often precede laws but are then supported, maintained, and extended by laws" (AXELROD, 1997, p. 61). Embora nem todos obedeçam às normas, a lei obriga a todos. A lei tira o custo de garantir a norma dos próprios indivíduos e da coletividade, institucionalizando-o. Por outro lado, sabe-se que algumas leis não são cumpridas em razão de limitações impostas pelas práticas já arraigadas socialmente. Por vezes, leis são apenas suplementos às normas, provendo clareza para essas. Para Axelrod, há complementaridade entre leis e normas porque as normas se formalizam em leis enquanto essas validam as normas, num círculo vicioso (fraquezas complementares) ou virtuoso (forças complementares).

Se a obediência ou não à norma define a reputação individual, trata-se de outro mecanismo a favor da adoção do comportamento prescrito para apenas alguns indivíduos e papéis sociais ou vinculados à coletividade. Trata-se do princípio da sinalização, quando algo que simplesmente "é" torna-se um "dever ser" (AXELROD, 1997).

Os resultados de Axelrod (1997) pactuam com Weber. Um bem passa da disposição de $A$ para a de $B$, e da de $B$ para a de $A$. Ambos nutrem a esperança de que a outra parte se comportará de maneira correspondente à intenção própria, assim como na estratégia vencedora olho por olho $(1997,2010)$. Portanto, a existência de ordem externa, aparato coativo ou desaprovação social, assim como pressupor o reconhecimento subjetivo de qualquer norma como 'obrigatória' ou ainda a crença de que a parte contrária o faça seriam desnecessários. No entanto, como vimos, o processo de racionalização e sua tradução nas relações econômicas impessoais característico das sociedades modernas, a garantia externa e o instrumento do contrato se tornaram fundamentais para assegurar o cumprimento das relações econômicas.

\footnotetext{
Para Weber, o racionalismo é um traço essencial do capitalismo, mas a racionalidade é vista não como um pressuposto do comportamento humano (como na teoria econômica), e sim como uma variável que evoluiu historicamente (Swedberg, 2005: 62); o processo de evolução do comportamento racional - ou racionalização da conduta - implica, essencialmente, substituir a submissão ao costume (que geralmente não envolve nenhuma reflexão quanto à ação e suas finalidades) pela adaptação planejada a uma situação objetiva de interesses. (WEBER, 1964, p. 24 apud MELO, 2006, p. 6)
}

Pode-se considerar que o resultado de Axelrod e de North (ao reforçar que transações duradouras possuem custos de transação menores em razão da diminuição da incerteza nas transações) é consoante com as conclusões weberianas acerca das regularidades. Como confirmam as citações supra e subcitada, Weber confirma que a continuidade da relação entre os agentes é definidora de seu comportamento. 
(...) o direito, a convenção e o costume de modo algum são os únicos poderes com os quais se conta e se pode contar como garantes de um comportamento prometido por outra pessoa, ou, de outra forma, considerado como um dever dela, mas que, junto com esses garantes, importa sobretudo o interesse próprio da outra parte na continuação de determinada ação consensual como tal. (WEBER, 1999, p. 222)

Assim, Weber considera as convenções sociais extremamente importantes, mas defende que a condição das decisões tomadas e da submissão ou não às regularidades sociais é o interesse individual da ação racional com vistas a fins. Logo, o descumprimento das orientações (apresentadas sob a forma de normas e convenções) diante da continuidade da relação dentro da instituição e do relacionamento daqueles que ali estão, é significativamente maior na narrativa 1 do que a narrativa 2.

Quem descumpre a regra na fila do refeitório pode entender que sua conduta não terá sanções que provoquem nele a vontade de se submeter à regularidade. Entretanto, isso pode ser uma interpretação limitada e imediatista que desconsidera custos de transação ${ }^{17}$. Os comportamentos possíveis a Z pressupõem a crença de que quem descumpre cria um ônus para o superior e/ou para toda a organização ao criar prerrogativas de descumprimento ou, na linguagem de Axelrod, constranger a todos, embora não haja metanormas implicadas. Isso porque ninguém será punido, por não punir um desertor, embora possa haver um sentimento de raiva e indignação perante o descumprimento de um desertor. Como vimos, existe não apenas a possibilidade de 'dar parte', o que o desertor pode considerar que não acontecerá, como também o próprio reforço à regra promovido pelo superior, dependendo da situação apresentada, pode ser acompanhado de reforços negativos mais ofensivos, como uma terceira possibilidade de retaliação subjetiva futura. Essa poderia ocorrer à medida que Z venha a ser responsável por Ihe designar ofícios, em que poderá responder ao'insulto moral' sentido. No caso do ônibus, o caráter das relações sociais formadas é transitório devido ao espaço social em que ocorre ser 'em trânsito', e por haver rotatividade entre os membros a cada pequeno intervalo de minutos. Ainda assim, não impediria a ocorrência de reprovações sociais simples até retaliações verbais mais ofensivas ou agressões físicas.

Para Bicchieri (2006), a conformidade à convenção existe porque ao indivíduo é conferida uma vantagem, obtida com o comportamento oportunista ou cooperativo, visando construir confiança e reputação suficientes para sustentar a relação estabelecida. As definições de Bicchieri, como muitas da NEl, observam a conformidade a partir das implicações da escolha racional individual ${ }^{18}$. Embora a autora considere a inserção do indivíduo em um contexto institucional, o custo da desobediência à convenção é estritamente individual, sem sanção social implicada nesse custo. Na narrativa 2, como não existe necessidade ou vontade de construir confiança, a possibilidade do ato de não ceder o lugar ${ }^{19}$ virar hábito não é entendida como uma problemática sob o ponto de vista social, porque seria 'apenas' o rompimento da regularidade, da convenção. Para North também pode valer a pena 
não cooperar em trocas impessoais entre indivíduos anônimos em interações não repetidas.

Se descumprir convenções sociais não incorre em sanções, Bicchieri aproxima convenções do conceito weberiano de costumes. Para Weber, costumes diferem das convenções porque essas são condutas garantidas externamente pela probabilidade de que o comportamento contrário enfrente uma reprovação geral - que pode ocorrer em níveis variados - em determinada comunidade. Sua diferença para a norma é que esta conta com um aparato coativo - grupo de pessoas autorizadas a fazer valer as regras - para agir contra aqueles que as descumprem. Ressalta-se em Weber que, embora a convenção não conte com esse aparato coativo, seu descumprimento pode incorrer em sanções, porque levada às ultimas consequências, a reprovação social pode levar à exclusão do individuo do grupo social (WEBER, 1999), ou de uma empresa em um grupo corporativo, de um país em uma convenção internacional, entre outros.

Para Bicchieri (2006), normas sociais seriam centradas nas expectativas dos demais membros do grupo de que será cumprida e, portanto, obedecida por toda a coletividade (muito semelhante ao conceito weberiano de convenções). Sua definição se relaciona a uma situação específica, quando qualquer membro de um grupo adota a norma, possuindo preferências condicionais. Assim, há uma predisposição a obedecer à norma social, como a probabilidade e as expectativas da outra parte apontadas no texto de Weber, e somente se os indivíduos acreditarem que suas expectativas serão satisfeitas é que estarão dispostos a obedecê-la. Tais preferências existem porque qualquer membro do grupo possui expectativas:

I. Empíricas: quando o indivíduo acredita que o grupo que a adota é parcela significativa da população;

II. Normativas: aquelas em que o indivíduo acredita que grande número de pessoas espera a obediência à norma na situação que ela se aplica;

III. Normativas com sanções: quando há sanção social informal (não legal), como censura velada ou aberta por parte do grupo, ostracismo e/ou desonra para os que desobedecem (BICCHIERI, 2006, p. 8 apud FIANI, 2011, p. 140).

Assim como os indivíduos possuem uma expectativa pela obediência alheia, também podem demonstrar reprovação, em caso de desobediência. Para Bicchieri, expectativas normativas, com ou sem sanções, é a característica especial das normas sociais em relação às convenções porque o único ônus que incorreria ao indivíduo descumpridor das convenções sociais seria a perda da oportunidade para coordenarse com outros. Contudo, observando como a coordenação aparece em estudos da NEl, acredita-se que esse ônus possui uma implicação mais relevante que o rompimento com o costume para Weber.

As "normas sociais", centradas nas expectativas normativas, contribuem para evitar o comportamento oportunista (como a norma jurídica e a convenção em Weber), à medida que ele corresponde a um desvio do comportamento cooperativo. Bicchieri (2006) e Axelrod (2010) concluem que as "normas sociais" que emergem 
espontaneamente são capazes de estabelecer as regras para favorecer a cooperação, minimizando o agir oportunista e, consequentemente, os custos de transação. Weber (1999) reforça esse argumento apenas nos casos de sociedades mais tradicionais, porque na moderna sociedade capitalista ele acredita que a garantia externa do aparato coativo é indispensável porque são muitas as formas e 'tentações' ao comportamento oportunista, assim como North (1990).

Weber (1999) buscava explicar a sociedade pela compreensão dos sentidos que os indivíduos atribuíam as suas ações, bem como os efeitos da conduta individual em outros indivíduos. Seus estudos, aqueles especificamente da área de sociologia econômica, buscaram entender os fenômenos econômicos a partir da ação social (ação individual ocorrida na esfera social) e do papel das regularidades exteriores a essa conduta, orientando-a. Analisou e tipificou os reais motivos das ações sociais, observando se realmente era a institucionalização da norma que orientava os comportamentos, o que observou ser apenas um dos motivos. Não apenas entendia as regularidades como forças sociais importantes (outros motivos socialmente reguladores e garantidores da ordem), mas também não as consideravam determinantes da conduta, ao defender que o interesse individual na continuidade das relações era crucial na observância ou não dessas orientações.

Neste artigo, é preciso observar a ordem jurídica do ponto de vista sociológico, isto é, investigando o que ocorre de fato ${ }^{20}$, a vigência ou validade empírica ${ }^{21}$ das regularidades. Assim, ultrapassa-se o que é apenas normativo (objeto de uma análise ou ponto de vista "puramente" jurídicos), combinado essa validade empírica à existência da condição da norma/direito: "uma forma específica de associação para fins de coação jurídica, que pode ser física ou psíquica, realizadas por um aparato coativo" (WEBER, 1999, p. 213).

Essa definição se assemelha à distinção entre Direitos de jure e Direitos de facto (SHAGLER, OSTROM, 1992), ao discutir direitos de propriedade. Os primeiros se apresentam como regra, estabelecidos pela autoridade política que detém os meios para fazê-los cumprir (o aparato jurídico weberiano) e devem ser obedecidos por todos. Isto é, são formalmente reconhecidos por todos e há instrumentos legais reconhecidos pelo Estado para reforçá-los. Já os direitos de facto são os direitos de propriedade reconhecidos pela comunidade, podendo existir simultaneamente, sobrepor-se, complementar-se, entrar em conflito entre si ou com os direitos de jure. Seriam direitos de facto enquanto não fossem reconhecidos pelas autoridades governamentais. Os direitos de jure e de facto afetam os incentivos individuais, norteando a conduta desses indivíduos diante dos resultados que pretendem atingir (Schlager \& Ostrom, 1992). Ostrom, portanto, confere grande importância à escolha individual.

$\mathrm{O}$ direito de jure se aproxima do que Weber entende como Direito ${ }^{22}$. Para ele, o Direito é uma ordem com probabilidade de vigência empírica, definido pela existência de aparato coativo para seu cumprimento que lhe confere legitimidade garantida externamente. Quando essa garantia é monopólio do Estado, por meio da força física, 
trata-se do Direito Estatal. É um conjunto de normas gerais, abstratas e impessoais e, por isso, imparciais. Entretanto, nem sempre o Direito foi dissociado da realidade (direito de jure e de facto), com ou sem validade empírica, ou como verbalizado no Brasil 'lei que pega/lei que não pega", traduzindo a distância entre formulação e prática jurídica, bem como à descrença/ausência de validade empírica nas regras sancionadoras do comportamento em caso de descumprimento. Assim, ser direito de Jure (Ostrom) ou Direito (Weber) não assegura validade empírica à norma jurídica, e a ausência dessa validade empírica pode indicar que ela é dissonante dos valores presentes nas regularidades sociais (as convenções weberianas e o direito de facto em Ostrom).

Pouco espaço resta para a consideração dos efeitos reais das normas, e mesmo quando se reconhece que existam, a relação entre norma e realidade é tida como problemática, algo que não pertence ao mundo jurídico. A relação 'entre o dever-ser da norma e o ser da realidade natural' coloca-se na conexão entre validade e eficácia da norma, reconhecendo-se, contudo, que eficácia 'é uma qualidade da conduta efetiva dos homens e não (...) do direito em si'; em outras palavras, é um atributo do mundo real e não do normativo. (MELLO, 2006, p. 3)

Há uma distinção entre costumes e convenções em Weber, fundamentada na defesa que descumprir um costume é algo menor que descumprir uma convenção. Enquanto sobre o primeiro não recai consequências, porque não possui garantias externas de validade, sendo visto apenas como uma 'saída de rotina', isto é, uma alternativa ao próprio costume, descumprir uma convenção pode ser alvo de reprovações sociais relevantes (reforçando sua validade) e, em último caso, levando à exclusão social.

O conceito de "convenções sociais" de Bicchieri (2006) equivaleria ao de usos e costumes em Weber. Uso se refere ao que de fato é realizado, mediante o interesse individual, baseado nas expectativas previamente formadas: uma ação racional com vistas a fins pressupondo determinado comportamento da outra parte. Assume caráter de hábito e não o é, apenas porque quando se torna regular e duradouro, transformase em costume. Ambos possuem caráter voluntário, por aceitação irrefletida, uma simples imitação. Contudo, se o indivíduo não se voluntaria porque pode/deseja (ação racional com vistas a fins) fazer de outra forma, isso não ocasiona problemas para a ordem social.

Weber defende que meios coativos não violentos podem trazer efeitos muito seguros para a observância das regularidades ${ }^{23}$ e até meios coativos jurídicos podem ser reforçados pelos aparatos coativos das comunidades, ou associações, como Weber apresenta. Os meios coativos não violentos reforçam para a comunidade as regularidades que funcionam como a orientação das ações. Sua observância por todos os seus membros é dispensável para entender tal prescrição como norma, porque o fato de alguns a desobedecerem não significa que a regra não é válida. Há sempre a possibilidade do descumprimento consciente de uma regra de acordo com o interesse em cada situação (WEBER, 1999, p. 218-219). A narrativa 1 exemplifica isso. 
As regularidades orientadas por regras e não por hábito inconsciente são, em parte, regularidades de costume e convenção. Contudo, na maioria das vezes, são também máximas da ação subjetivamente racional referente a fim, em interesse individual. Estes contam com sua eficácia e, frequentemente, podem fazê-lo, de modo objetivo, em virtude de relações associativas ou consensos especiais, embora não protegidos por coação jurídica (WEBER, 1999, p. 218-219).

Assim, Weber aponta que as razões da obediência às regularidades sociais são:

1. Porque o mundo circundante aprova ou desaprova o oposto;

2. Porque os indivíduos se habituam inconscientemente à ordem (às regularidades) da vida sentida como costume. (WEBER, 1999, p. 215-219)

Além disso, a vigência empírica de uma norma e/ou convenção estaria diretamente vinculada aos interesses individuais em razão das oportunidades que dela resultam. No caso das normas, utilizamo-las para criar oportunidades ou garanti-las, baseandonos no direito estatuído quando se pactua (um contrato) ou se impõe ao contrato uma norma jurídica.

Dessa forma, pode-se dizer que a coação jurídica, ao fazer de um costume um dever jurídico, quase nada acrescenta em sua eficácia e, quando contra ele se dirige, frequentemente fracassa na tentativa de influenciar as ações efetivas. A convenção (meros costumes convertidos em normas obrigatórias, ainda que não institucionalizadas legalmente, garantidas por coação psíquica) pode determinar muito mais os comportamentos que o aparato de coação jurídica. Isso conforma a tradição, que ocorre quando a convenção se apodera da regularidade das ações (transformando a ação de massas em uma ação consensual, lembrando que consenso não significa que todos os indivíduos obedecem, apenas que todos a admitem como regra norteadora da conduta). A repetição regular por imitação refletida ou adaptação às circunstâncias exteriores da vida confere a essa repetição o caráter de algo normativamente ordenado (WEBER 1999, p. 215-216), assim como a narrativa 2.

Portanto, Weber não antagoniza a ordem jurídica e a ordem convencional, porque também a convenção é apoiada por coação psíquica ou mesmo física, por vezes imposta pelo aparato coativo. $O$ que caracteriza a ordem jurídica é a estrutura sociológica da coação, desde o aparato coativo do Estado (third-party enforcement) até sacerdotes no caso de sociedades na qual a religião assume o papel ordenador (WEBER 1999, p. 219-220).

\section{Sobre convenções sociais: Weber e a NEI}

$\mathrm{O}$ argumento weberiano mais elucidativo para a crítica empreendida à NEI defende ser errônea a ideia de que não é 'exigido' ao indivíduo o cumprimento dos deveres convencionais e que a consequência é a segregação voluntária de uma relação associativa de caráter igualmente voluntário. Há diversas maneiras de segregação 
involuntárias - desde níveis de afastamento pouco significativos à exclusão completa da associação/comunidade. A força das convenções é tamanha que é possível encontrar exemplos de associações que renunciam ao caráter jurídico de suas ordens convencionais porque supõem que a desaprovação social resultante da infração, e suas consequências indiretas, são sanções suficientes. Esta força é comum em sociedades cuja crença subjetiva na vigência empírica de semelhantes normas é amplamente difundida, gerando um consenso; sociedades em que a probabilidade de reprovação social cria uma garantia convencional ou a existência do aparato coativo gera 'garantia jurídica' (WEBER, 1999, p. 219).

Consequentemente, quando a repetição é tanta que as pessoas se convencem de que suas ações - e não a regra jurídica que se pretende válida - correspondem à norma, o poder coativo garantidor deixa de impor a observância dessa regra. Por isso Weber considera que a regulação jurídica é apenas um aditivo (e não a garantia principal) e a racionalidade estatuída, apenas um componente da motivação para a ação, que aparece tardiamente e com intensidades variadas. As origens das regularidades tendem a ser obscuras, surgindo na prática cotidiana - via impulsos e instintos - de um comportamento adaptado às necessidades dadas da vida, que não foi condicionado ou modificado por uma ordem jurídica (WEBER, 1999, p. 223).

As conclusões de Weber concordam com as das reflexões antropológicas sobre o jurídico ${ }^{24}$, indicando que as consequências do não cumprimento das 'obrigações morais e/ou sociais', das 'regras informais' e das 'instituições' são, de fato, sanções sociais. Autores da NEl citados nesse artigo embora tratem dessas questões e do papel delas na assimetria de informações, dos contratos e dos custos de transação, parecem desconsiderar as consequências de descumprimentos a alguns tipos de regularidades. O descumprimento das expectativas mútuas é mais frequente que se supõe, tanto nas sociedades modernas (NORTH, 1990) quanto nas sociedades primitivas ${ }^{25}$. "Normas e convenções sociais" são conceitos que se relacionam à coordenação informal e à formação de uma ordem social que, embora dinâmica, encontra neles elementos para sua permanência e organização. Os fatores de coordenação e cooperação, bem como as falhas e os conflitos dela decorrentes, podem encontrar sua justificativa em elementos da esfera cultural que não são suficientemente elaborados nos estudos da $\mathrm{NEI}^{26}$.

\section{Notas sobre o início da cooperação}

Ceder ou se abster? Predispor-se ou Contrapor-se? No Direito discutido por Durkheim, um crime não ofende apenas a vítima, mas toda a sociedade ordenada pela regra desrespeitada. Toda infração é uma afronta ao Estado, ao conjunto de normas institucionalizado em seu Direito, uma vez que o Estado assume a defesa das normas que criou, possibilitando o bem-estar social. Assim também as regularidades nãoinstitucionalizadas - as convenções. Contudo, nesse caso, a ofensa é contra a sociedade 
como coletividade organizada, gerando diversos níveis de reprovações e tensões sociais que geram as metanormas.

As duas narrativas apresentadas ilustram situações diversas. Na primeira, os indivíduos são membros de uma mesma organização e continuarão a se relacionar ainda que em níveis de intensidade ou proximidade, hierárquica ou situacional, diferentes. Na segunda, os indivíduos desertores e os sancionadores variam, bem como as expectativas empíricas e normativas (com ou sem sanções) de cada um.

Para Z, o indivíduo que descumpre a norma na OM, descumpriria a convenção no ônibus porque o'desvio' da norma na situação 1, poderia indicar má índole. Conclui-se aqui que as duas situações possuem implicações distintas, embora caiba indagar se seria possível considerar ambos como infrações com as mesmas motivações, como defende $Z$ ?

Nas OMs, quem quer que deva ceder a prioridade e não o faz é, de fato, um desertor, porque descumpre normas da sua organização profissional, com a qual pactuou ao tornar-se membro dela voluntariamente. Assume, portanto, a obrigatoriedade de respeitar suas normas que priorizam hierarquia e disciplina como valores centrais. Entretanto, ressalta-se que, tanto pode ser interpretado como não descumprimento e apenas um comportamento de maneira a não se prejudicar, uma vez que $Z$ não clamou seu direito naquele momento, quanto como comportamento conscientemente desertor ao discordar das normas da OM.

Desviar de uma norma regimental é assumir as consequentes sanções. Há três formas mais comuns: a legal, imposta pelo aparato coativo da OM; a moral, manifesta pelo desprezo de seus colegas ${ }^{27}$ e a vendeta, a vingança pessoal, o "dar o troco" em algum momento futuro. Embora ressaltemos o papel da sanção moral nos estudos weberianos, esta pode ser sentida de forma insignificante ou efêmera para provocar um desejo de mudança de comportamento no desviante. Isso seria previsível em indivíduos que não compartilham dos valores morais da organização, por ser neófito e ainda desconhecê-los ou, conhecendo-os, discordar deles com ou sem motivos lógicos ou nobres para tanto.

\section{Conclusão}

Conclui-se que os conceitos weberianos - usos, costumes, convenções e normas jurídicas - são mais criteriosamente elaborados, dentro de uma lógica coerente com a sociologia compreensiva.

Espera-se que o contraponto weberiano tenha esclarecido porque compreender normas e convenções sociais, bem como suas consequências, é fundamental aos estudos sobre cooperação. Autores das Ciências Sociais, que se dedicaram à compreensão do Direito (reino das normas legais) e do Jurídico (englobando diversos mecanismos de manutenção da ordem social) discutindo a regulação social por mecanismos formais e informais, reforçam a relevância dos últimos. 
Ao tratar de "normas sociais", a literatura da NEI observada ora pactua ora diverge das conclusões sociológicas. Pactua mais que diverge, embora a análise das convenções sociais e as implicações de seu rompimento sejam superficiais, admitindo Weber como o referencial comparativo. Já sobre "convenções sociais" pouco é dito, e a ausência do mecanismo da sanção social ao seu descumprimento, como defendido nos autores da NEl abordados, parece um contrassenso.

Nos ambientes políticos e econômicos contemporâneos - onde sanções formais estão estabelecidas e as informais, por vezes, aparecem sob a forma de sanções comerciais $^{28}$ - seria imprudente desconsiderar os efeitos funestos de descumprir convenções sociais. Os párias sociais, os estigmas, os mecanismos de administração de conflitos recusados por motivos pessoais, ou porque a cultura não enxerga saída além das que são habituais, pode aparecer tanto na narrativa 1 (interações com expectativa de continuidade), quanto nos exemplos de Axelrod (2010). Os autores da NEI não desconsideraram as sanções decorrentes do rompimento com as normas e convenções sociais por completo, mas não compreenderam a importância de suas consequências. Exatamente aqui, entende-se que a análise neoinstitucionalista mais se beneficia de um contraponto weberiano sobre resolução de conflitos e, consequentemente, coconstrução de cooperação.

\footnotetext{
Notas

' Uma versão preliminar deste artigo, de autoria única, foi apresentada no V Congresso Anual de Direito e Economia, promovido pela UFPE/UFPB/UFAL/UCB, em 2012. O presente artigo resulta de sua revisão e co-autoria.

${ }^{2}$ Nova Economia Institucional.

${ }^{3}$ OMs são instituições militares regidas pelos seus códigos; base de trabalho de todos os militares das forças armadas.

${ }^{4}$ Essa narrativa relata eventos de uma instituição militar de formação de futuros oficiais, cuja identificação não é imprescindível. Admitindo hierarquia e disciplina como valores maiores nas Forças Armadas, supõese que a situação apresentada poderia ocorrer em qualquer uma delas.

5 "Z" denomina aquele que, na situação, for o hierarquicamente superior.

${ }^{6}$ Disponível em http://idososeseusdireitos.blogspot.com.br/2010/04/usuarios-nao-respeitam-assentos. html Acessado em 29/04/2012.

${ }^{7}$ Quando norma não vier acompanhado de adjetivação, ele estará se referindo às normas jurídicas, legais. ${ }^{8}$ Ressalta-se em itálico alguns conceitos, especialmente os que traduzem as diferenças entre a teoria weberiana sobre a ordem social, especialmente a ordem jurídica e econômica, e a defesa da NEl.

9 Definição: "(...) a ordem social constituída por regras de comportamento tacitamente aceitas pela sociedade" (FIANI 2011, p. 106).

10 Entre os quais Malinowski, 2003; Radcliffe-Brown, 1973; Maine, 1917; Mauss, 1981.

${ }^{11}$ A literatura da teoria dos jogos sobre cooperação aponta que quanto maior a probabilidade da interação se repetir - isto é, que haja transações futuras envolvendo as mesmas partes - maior a probabilidade de que as partes cumpram os termos do contrato sem a necessidade dos mecanismos de enforcement.

${ }^{12}$ Toda ordem social é formada por comportamentos legitimados pela coletividade. Baseado neles, o indivíduo se relaciona com os demais por meio de expectativas resultantes dos usos, costumes, normas e convenções (WEBER, 1999).

${ }^{13}$ Ao discutir interesses, trata-se da ação racional com vistas a fins, com vistas a valores ou ainda a ação afetiva e a tradicional. Em todas elas, o comportamento interessado está sendo influenciado.
} 
$14 \mathrm{Na} \mathrm{NEl}$, os conceitos de "normas e convenções sociais" podem ter seus significados apresentados também sob outros conceitos como 'regras e/ou instituições informais', 'obrigações sociais e/ou morais', 'regularidades sociais' entre outros. Essas mudanças decorrem dos programas de pesquisa e das diferentes disciplinas.

${ }^{15}$ No entanto, há características marcantes aqui que faltam em outros jogos. 1. O primeiro jogador começa cooperando; 2. Perdoa-se o outro jogador no momento em que ele volta a cooperar (só imitando a rodada anterior, exigindo pouca racionalidade) e 3. Trata-se de uma estratégia muito simples. (AXELROD 2010, 1997 apud FIANI 2011, p. 144)

${ }^{16}$ A estratégia vencedora do torneio, a olho por olho, é uma estratégia cooperativa vinculada a um conhecimento anterior.

${ }^{17}$ Em breve definição, custos de transação são todos os custos envolvidos para que uma transação aconteça, desde os materiais aos imateriais, tais como reputação, tempo investido, processo, informação, entre outros. É um dos conceitos centrais nos estudos da nova economia institucional. Para uma discussão mais extensa do conceito, Cf. Fiani (2011).

${ }^{18}$ Para a teoria econômica convencional, que desconsidera a importância das regularidades, a fonte das escolhas econômicas é o interesse racional individual. Weber tem o mérito de conciliar a influência considerável que remete à ação racional individual com vistas a fins com o papel direcionador e inerente das regularidades sociais na escolha dos indivíduos.

19 Trata-se aqui dos $90 \%$ dos assentos que não são reservados aos idosos, porque somente nesses casos há comportamento convencional e não o comportamento orientado pela norma jurídica - 10\%.

${ }^{20}$ Isto é, o quanto aquele comportamento, em termos weberianos, entendidos como ação social, tem a probabilidade de se verificar, uma vez que é considerado parte da ordem legítima (quando as regras daquela 'ordem' são percebidas como obrigatórias).

${ }^{21}$ Pode-se falar em vigência empírica quando o aparato coativo funciona em medida relevante, mesmo sem quaisquer meios coativos físicos ou quando sua inobservância apresenta consequências jurídicas (para a qual há instância de coação jurídica).

22 Enquanto o direito de facto se aproxima do conceito weberiano de convenções.

${ }^{23}$ Embora os autores da NEI analisados tenham percebido isso, não reforçaram ou aprofundaram tal argumento, como Weber o fez, décadas antes.

${ }^{24}$ Entre eles, Maine (1917), Malinowski (2003), Radcliffe-Brown (1971) Mauss (1981), Geertz (1989, 1999).

${ }^{25}$ Nos primeiros textos da Antropologia Jurídica, o foco recaía sobre a ordem social criada pelos costumes e o nível de desenvolvimento da regulação em tais sociedades. Costumes, convenções, normas e resolução de conflitos eram palavras-chaves de então, destacando o peso das sanções sociais severas que recaíam sobre aqueles que desobedecessem.

${ }^{26}$ Entre os estudos antropológicos mais recentes sobre cultura como mecanismo de coordenação e cooperação no Brasil, encontra-se Migueles (MIGUELES, LARAIA, COSTA 2007; MIGUELES In ZANINI 2008: p. 41-63) e Zanini (org., 2008). Ambos estão preocupados com os entraves criados pelos passivos culturais brasileiros que geram custos de transação pelas perdas de oportunidade de cooperação nas organizações.

${ }^{27}$ Tanto os hierarquicamente superiores quanto subalternos que valorizam a adoção do comportamento prescrito por todos os membros daquela organização, entendida como uma comunidade.

${ }^{28}$ Que podem tornar-se legais e com justa causa, como o embargo à carne vermelha, em momentos de surto de vaca-louca. 


\section{Referências bibliográficas}

ABRAMOVAY, R. Entre Deus e o diabo. Tempo Social, Revista de sociologia da USP, 16(2), 36. 2004. Disponível em: <http://www.scielo.br/pdf/ts/v16n2/v16n2a02.pdf >. Acesso em: 15 out. 2013.

AXELROD, R. A evolução da cooperação. São Paulo: Leopardo Editora. 2010.

. The complexity of cooperation: Agent-based models of competition and collaboration. Princeton University Press. 1997.

BICCHIERI, C. The grammar of society: The nature and dynamics of social norms. Cambridge University Press. 2006.

DURKHEIM, É., \& MAUSS, M. Algumas formas primitivas de classificação. Ensaios de sociologia. 1981. p. 399-455.

FIANI, R. Cooperação e conflito: instituições e desenvolvimento econômico. Rio de Janeiro: Elsevier. 2011.

GEERTZ, C. A interpretação das culturas. Rio de Janeiro. LTC. 1989.

. O saber local: fatos e leis em uma perspectiva comparada. O Saber Local. 1999. p. 249-356.

MAINE, H. S. Ancient Law. Reprint, London: JM Dent. 1917.

MALINOWSKI, B. Crime e Costume na Sociedade Selvagem. Tradução de Maria Clara Corrêa Dias. Brasília: UnB. 2003.

MAUSS, M. Ensaio sobre a dádiva: formas e razão da troca nas sociedades arcaicas. In: Sociologia e Antropologia. Vol. Il. São Paulo: Cosac \& Naify. 2003.

MELLO, M. T. L. Direito e economia em Weber. Revista Direito GV,2(2). 2006. pp. 45-65.

MIGUELES, C. Cultura como ativo intangível. ZANINI, M. T. Gestão integrada de ativos intangíveis. Qualitymark Editora Ltda. 2008.

MIGUELES, C., DE SOUZA, G. C., \& LAFRAIA, J. R. B. Criando o hábito da excelência. Qualitymark Editora Ltda. 2006.

NORTH, D. C. Institutions and economic growth: An historical introduction. World development, 17(9). 1989. p. 1319-1332. Disponível em: <http://www.econ.ethz.ch/teaching/ variee/2011_north_presentation.pdf>. Acesso em: 09 nov. 2013.

. Institutions, institutional change and economic performance. Cambridge university press. 1990.

. Institutions, ideology, and economic performance. Cato J., 11, 477. 1991. Disponível em: <http://object.cato.org/sites/cato.org/files/serials/files/cato-journal/1992/1/cj11n3-11.pdf>. Acesso em: 08 set. 2013.

. Economic performance through time. The American economic review. 1994. p.359-368. Disponível em: <http://classwebs.spea.indiana.edu/kenricha/classes/v640/v640\%20readings/ north\%201994.pdf.> Acesso em: 12 mar. 2013.

OSTROM, E. Governing the commons: The evolution of institutions for collective action. Cambridge university press. 1990.

RADCLIFFE-BROWN, A. R. Religião e sociedade. Estrutura e função na sociedade primitiva. Rio de Janeiro: Vozes. 1973

SCHLAGER, E., \& OSTROM, E. Property-rights regimes and natural resources: a conceptual analysis. Land economics. 1992. p. 249-262. Disponível em: <http://www.jstor.org/

stable/3146375>. Acesso em: 27 mai. 2012. 
VOSS, T. Game theoretical perspectives on the emergence of social norms. HETCHER, Michael; OPP, Karl-Dieter (eds). Social norms. New York: Russel Sage Foundation. 2001. p. 105-136.

WEBER, M. Economia e sociedade: fundamentos da sociologia compreensiva. v. 1. Brasília: UnB. 1999. p. 209-227.

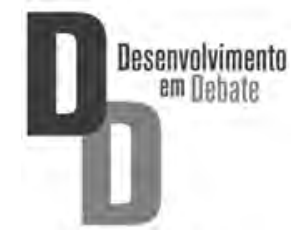

